\title{
Liquidus Temperature Design of Lead-Free Solder
}

\author{
Kenichiro Suetsugu ${ }^{1}$, Akio Furusawa ${ }^{1}$, Masato Tanaka ${ }^{2}$, Hiroaki Takano ${ }^{3}$, \\ Hideki Takehara ${ }^{4}$, Toshihiro Horiuchi ${ }^{5}$ and Kazumi Matsushige ${ }^{5}$ \\ ${ }^{1}$ Jisso Core Engineering Laboratory, Corporate Production Innovation Division, \\ Matsushita Electric Industrial, Co., Ltd., Osaka 571-8501, Japan \\ ${ }^{2}$ Engineering Team, FA Engineering Group, Matsushita Solution Technology Company, Osaka 571-8502, Japan \\ ${ }^{3}$ Mounting Analysis Team, Manufacturing Analysis Group, Matsushita Techno Research, Inc., Osaka 570-8501, Japan \\ ${ }^{4}$ SiP Development Section, Package Development Dept., Production Engineering Center, Corporate Manufacturing \& \\ Development Division, Semiconductor Company, Matsushita Electric Industrial Co., Ltd., Osaka 617-8520, Japan \\ ${ }^{5}$ Graduate School of Engineering, Kyoto University, Kyoto 615-8530, Japan
}

A method for designing lead-free solder was studied using the liquidus temperature of a 2-component eutectic solder in order to develop a high temperature lead-free solder. In this work, tests were done to obtain a targeted liquidus temperature of a 4-component lead-free solder based on the weight percentage of two sets of 2-component eutectic solders. This 2-component eutectic solder was assumed to be thermodynamically stable in itself. The weight percentages of five respective types of $\mathrm{Bi}-\mathrm{Cu}, \mathrm{Ag}-\mathrm{Cu}$ etc. eutectic solders were varied and the design temperature was predicted and compared against the measured liquidus temperature. In doing this, it was learned that the measured apparent liquidus temperatures were liniear with respect to the design temperatures. Similar studies were conducted into a medium temperature material of Sn$\mathrm{Ag}-\mathrm{Cu}$ and a low temperature material of $\mathrm{Sn}-\mathrm{Bi}-\mathrm{Ag}$. The measured temperatures of these solders also corresponded to the design temperatures.

(Received May 13, 2005; Accepted February 6, 2006; Published April 15, 2006)

Keywords: liquidus temperature, design, lead free, solder, eutectic solder

\section{Introduction}

Solder is said to date back some 5000 years. ${ }^{1)}$ Despite the long history, solder must now comply with the EU's RoHS Directive by July 2006. In compliance with the RoHS Directive, Matsushita Electric Industrial completely abolished the use of leaded solder at the end of 2002 by introducing lead-free solder. ${ }^{2)}$

Currently, development is underway to expand the scope of applicability of lead-free solder. In particular, there is growing need for a higher melting point solder of high lead content in bonding high frequency modules and PDP because of the high temperature of the process atmosphere. Research is therefore underway worldwide into a high temperature (250 to $320^{\circ} \mathrm{C}$ melting point) solder of $80 \%$ or higher lead content, but a workable material has yet to be found. This is because the investigated 2-component materials have yet to satisfy all of the requirements, to note a high melting point, bondability, stability and other solder characteristics. ${ }^{1)}$ With multiple component solders, because of the complexity of the material system, which is needed to ensure the required material properties, a great deal of time is needed to search for the right material composition, hence there are practical difficulties to surmount ahead of its materialization. ${ }^{1)}$

Therefore, we theorized how to efficiently determine the best composition of a multiple component solder with respect to liquidus temperature, designed some materials based on this theory and tested them with actual measurements. Next, we predicted the melting point of these high melting point solders based on the composition formulated according to this theory. Moreover, we predicted the apparent liquidus temperature of various lead-free solders.

\section{Melting Model for 2-Component Eutectic Solders}

In order to determine an alloy composition of high melting point for the solder, a 2-component eutectic solder was taken as the basic structure. Here, it was assumed that, if another 2-component eutectic solder of differing composition were added to the base 2-component eutectic solder, the two solders would not react with one another or, in other words, the material would be physically and chemically stable.

Accordingly, these metals $\mathrm{C}$ and $\mathrm{D}$ are in an eutectic state, as are metals $\mathrm{A}$ and $\mathrm{B}$. If mixed and melted together, the following two patterns are conceivable.

By the first pattern, if the $\mathrm{AB}$ or $\mathrm{CD}$ alloys are substances that would react when melted, such as A with $\mathrm{C}$ or A with D, then diverse physical and chemical reactions could occur. This possibility is illustrated in the model of Fig. 1(A). In model (A), various alloys form and the various melting points of these alloys affect one another, making the solder conceivably unstable.

The second pattern envisions minimal reaction between alloys $\mathrm{AB}$ and $\mathrm{CD}$, as shown in model Fig. 1(B). Minimal reaction means that the kinetic diffusion of these alloys is considerably slow and reactions between $\mathrm{AB}$ and $\mathrm{CD}$ apparently occur little. Here, if the alloys disperse within one another, temperature uniformity would be maintained, whereby stabilizing the melting point and making the material practical as a solder.

Based on these assumptions, this paper addresses alloy model (B) in which there is minimal reaction between alloys $\mathrm{AB}$ and $\mathrm{CD}$.

\section{Alloy Melting Point Estimation Theory}

\subsection{Melting point estimation formula for 4-component solder}

A 2-component alloy consisting of substances A and B was taken as the first metallic composition, as per the assumption of 2 [Fig. 2(a)]. The weight of A found in the eutectic alloy $\mathrm{AB}$ is given as $W_{2 \mathrm{~A}}$. The stable temperature when this alloy 


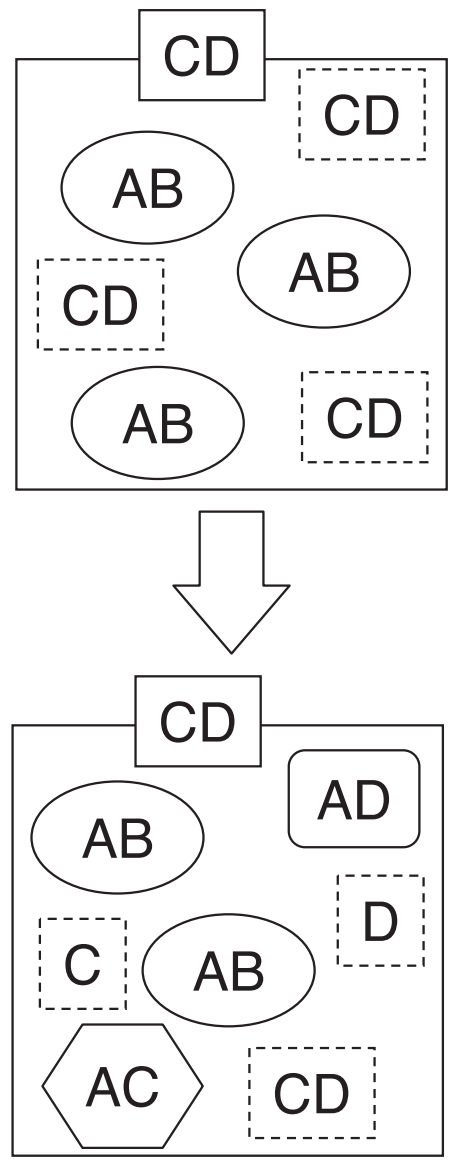

(A)

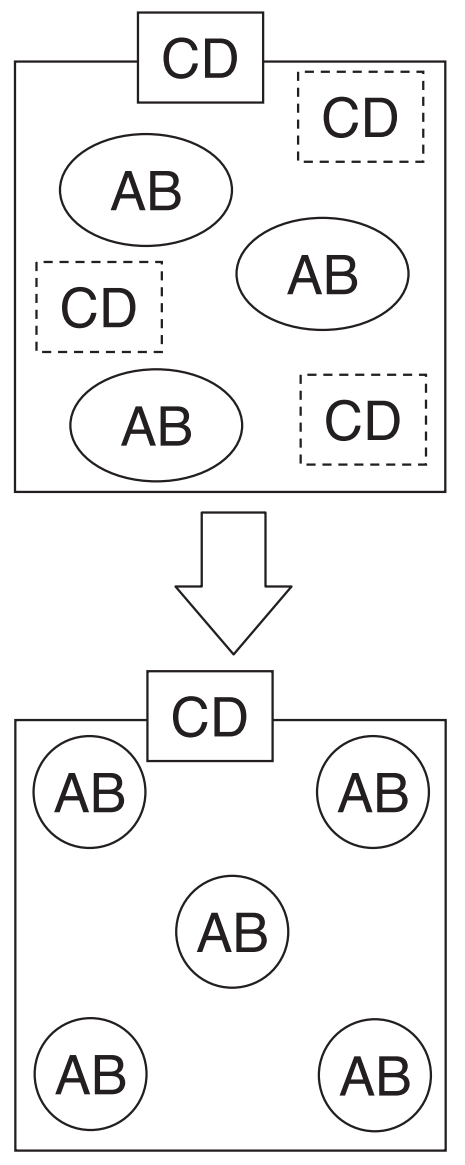

(B)

Fig. 1 Melting model for four 2-component eutectic alloys.

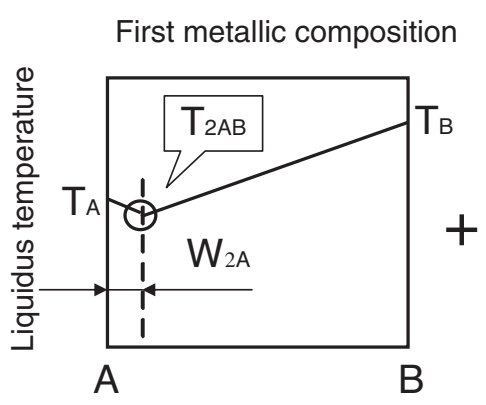

(a)

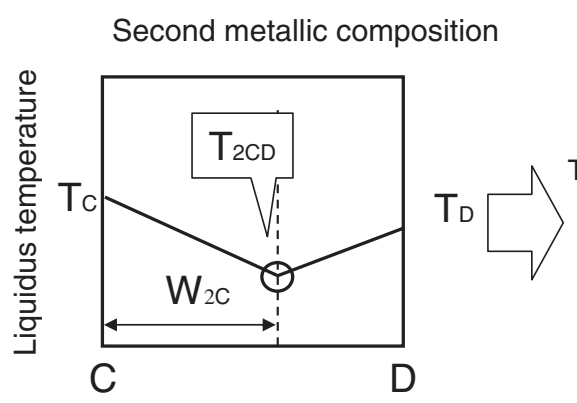

(b)

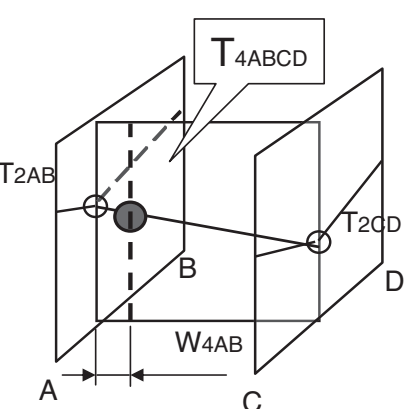

(c)

Fig. 2 Designing lead-free solders.

melts is given as $T_{2 \mathrm{AB}}$. Similarly, a 2-component alloy consisting of substances C and D [Fig. 2(b)] was taken as the second metallic composition. The weight of $\mathrm{C}$ found in the eutectic alloy $\mathrm{CD}$ is given as $W_{2 \mathrm{C}}$. The melting temperature of this alloy is given as $T_{2 \mathrm{CD}}$.

The temperature profile that connects the eutectic temperatures of the first and second metallic compositions is shown in Fig. 2(c). The condition for the temperature profile in Fig. 2(c) is only caused by the condition that A and C, or B and $\mathrm{D}$ can be reacted little. Here, the target temperature is $T_{4 \mathrm{ABCD}}$. Also, the entire material composition in this state is taken to be 1 and it was assumed that $T_{4 \mathrm{ABCD}}$ is on a straight line between $T_{2 \mathrm{AB}}$ and $T_{2 \mathrm{CD}}$. The weight of the eutectic crystal of substances $\mathrm{A}$ and $\mathrm{B}$ in the entire 4-component material is given as $W_{4 \mathrm{AB}}$ and expressed with formula (1).

$$
W_{4 \mathrm{AB}}=\left(T_{2 \mathrm{CD}}-T_{4 \mathrm{ABCD}}\right) /\left(T_{2 \mathrm{CD}}-T_{2 \mathrm{AB}}\right)
$$

The weight of substance $\mathrm{A}$ in the 4-component material, $M_{4 \mathrm{~A}}$, is obtained using $W_{4 \mathrm{AB}}$ in formula (2).

$$
M_{4 \mathrm{~A}}=W_{2 \mathrm{~A}} \times W_{4 \mathrm{AB}}
$$

The same is done for the weight of substance $B$ in the 4component material, using formula (3). 


$$
M_{4 \mathrm{~B}}=\left(1-W_{2 \mathrm{~A}}\right) \times W_{4 \mathrm{AB}}
$$

In this same line of thinking, the weights of substance $\mathrm{C}, M_{4 \mathrm{C}}$, and substance $\mathrm{D}, M_{4 \mathrm{D}}$, in the 4-component material are obtained with formulas (4), and (5).

$$
\begin{aligned}
& M_{4 \mathrm{C}}=W_{2 \mathrm{C}} \times\left(1-W_{4 \mathrm{AB}}\right) \\
& M_{4 \mathrm{D}}=\left(1-W_{2 \mathrm{C}}\right) \times\left(1-W_{4 \mathrm{AB}}\right)
\end{aligned}
$$

Using the five formulas in Section 3, we can estimate the target temperature, $T_{4 \mathrm{ABCD}}$, and determine the weight of each material in the solder.

The procedure for obtaining the target temperature, $T_{4 \mathrm{ABCD}}$, was as follows. The content weights of $\mathrm{A}, \mathrm{B}, \mathrm{C}$ and $\mathrm{D}$ of the 4-component solder were obtained using the aforementioned formulas (1)-(5). In other words, the content weights of elements A and B of the first metallic compound were identified and similarly so were those of elements $\mathrm{C}$ and $\mathrm{D}$ of the second metallic compound. These two eutectic solders were then melted and formed into alloys, then mixed in an electric furnace to make the desired 4-component solder. The solder was weighed by DSC and the liquidus temperature was measured. Because it is thinkable that some solid matter may exist in this liquid state solder, reference at this point to "liquidus temperature" is strictly intended to mean the "apparent liquidus temperature". In other words, it is possible for the apparent liquidus temperature, obtained using the two types of 2-component metallic compounds as the departure materials for the new eutectic solder and manipulating them as aforementioned, to agree with hypothetical values if the two compounds did not react together even when mixed at a temperature at which both should exist in the liquid state, and from this, surmise the desired liquidus temperature.

\section{Experiments}

\subsection{Predicting material composition of high melting point solder}

Using the method described in Section 3, materials consisting of two sets of 2-component eutectic solders were designed so as to prepare a solder of the desired melting temperatures. The composition was identified for five different solders of melting temperatures of 280, 310, 320, 330 and $360^{\circ} \mathrm{C}$. Here, in order to obtain these melting temperatures or higher in a product solder, $\mathrm{Bi}-\mathrm{Cu}\left(T_{2 \mathrm{AB}}=270^{\circ} \mathrm{C}, W_{2 \mathrm{~A}}=\right.$ $0.005)$ was selected as the first alloy and $\mathrm{Ag}-\mathrm{Cu}\left(T_{2 \mathrm{CD}}=\right.$ $779^{\circ} \mathrm{C}, W_{2 \mathrm{C}}=0.290$ ) was selected as the second. The composition of $\mathrm{Bi}-\mathrm{Cu}$ and $\mathrm{Ag}-\mathrm{Cu}$ was calculated for a target temperature of $280^{\circ} \mathrm{C}$ obtained with the five formulas in Section 3. Because of the $270^{\circ} \mathrm{C}$ melting point of $\mathrm{Bi}-\mathrm{Cu}$ and $779^{\circ} \mathrm{C}$ melting point of $\mathrm{Ag}-\mathrm{Cu}$, the composition of the former was identified as $98 \%$, and the latter, as $2 \%$. As a result, the composition was $\mathrm{Bi}-1.4 \mathrm{Ag}-1.1 \mathrm{Cu}$ at a design temperature of $284^{\circ} \mathrm{C}$.

Similarly, a design temperature of $308^{\circ} \mathrm{C}$ was calculated for a target temperature of $310^{\circ} \mathrm{C}$ using $\mathrm{Bi}-5.6 \mathrm{Ag}-2.7 \mathrm{Cu}$. A design temperature of $321^{\circ} \mathrm{C}$ was calculated using $\mathrm{Bi}-$ $7.0 \mathrm{Ag}-3.3 \mathrm{Cu}$ for a target temperature of $320^{\circ} \mathrm{C}$, a design temperature of $325^{\circ} \mathrm{C}$ was calculated using $\mathrm{Bi}-8.4 \mathrm{Ag}-3.8 \mathrm{Cu}$ for a target temperature of $330^{\circ} \mathrm{C}$, and a design temperature of $363^{\circ} \mathrm{C}$ was calculated using $\mathrm{Bi}-12.6 \mathrm{Ag}-5.5 \mathrm{Cu}$ for a target temperature of $360^{\circ} \mathrm{C}$.

The combinations of alloys were then changed and subsequently compounded, this time with $\mathrm{Bi}-\mathrm{Ag}$ as the first alloy and $\mathrm{Cu}-\mathrm{Ag}$ as the second.

Calculations were done using the five formulas in Section 3. Here, the design melting temperature of the $320^{\circ} \mathrm{C}$ target $(\mathrm{Bi}-10.2 \mathrm{Ag}-3.2 \mathrm{Cu})$ was $304^{\circ} \mathrm{C}$, that of the $330^{\circ} \mathrm{C}$ target $(\mathrm{Bi}-$ $15.4 \mathrm{~g}-5.5 \mathrm{Cu}$ ) was $320^{\circ} \mathrm{C}$, and that of the $360^{\circ} \mathrm{C}$ target $(\mathrm{Bi}-$ $11.5 \mathrm{Ag}-5.5 \mathrm{Cu}$ ) was $345^{\circ} \mathrm{C}$.

\subsection{Evaluation of prototype high melting point solder}

The various composition solders of Section 4.1 were made as follows. To obtain the targeted $T_{4 \mathrm{ABCD}}$, the content weights of A, B, C and D of the 4-component solder were calculated using formulas (1)-(5) of Section 3. In other words, the content weight of first eutectic solder composed of elements $\mathrm{A}$ and $\mathrm{B}$ in the 4-component solder was identified and similarly so was the content weight of second eutectic solder composed of elements $\mathrm{C}$ and D. These two eutectic solders were then melted in their respective designed content weights and formed into an alloy, which was then loaded into an electric furnace and melted at $500^{\circ} \mathrm{C}$. A small piece was sampled from each, and the solidus temperature and liquidus temperature were measured using a differential scanning calorimeter. Also, each of the alloy components was atomized in $\mathrm{N}_{2}$ to a particle size of 20 to $30 \mu \mathrm{m}$. The particles were then kneaded into a paste using flux. The resulting pastes were placed in an electric furnace and heated to observe the melting process. Cross-sections of the solders were also examined after melting and subsequent solidification.

\section{Results and Observations}

5.1 Ideal straight line and melting temperature of compounded 2-component eutectic solder

Figure 3 plots the designed and measured liquidus and solidus temperatures for the $\mathrm{Bi}-\mathrm{Ag}-\mathrm{Cu}$ solders described in Section 4. When made of $\mathrm{Bi}-\mathrm{Cu}$ and $\mathrm{Ag}-\mathrm{Cu}$ eutectics, the

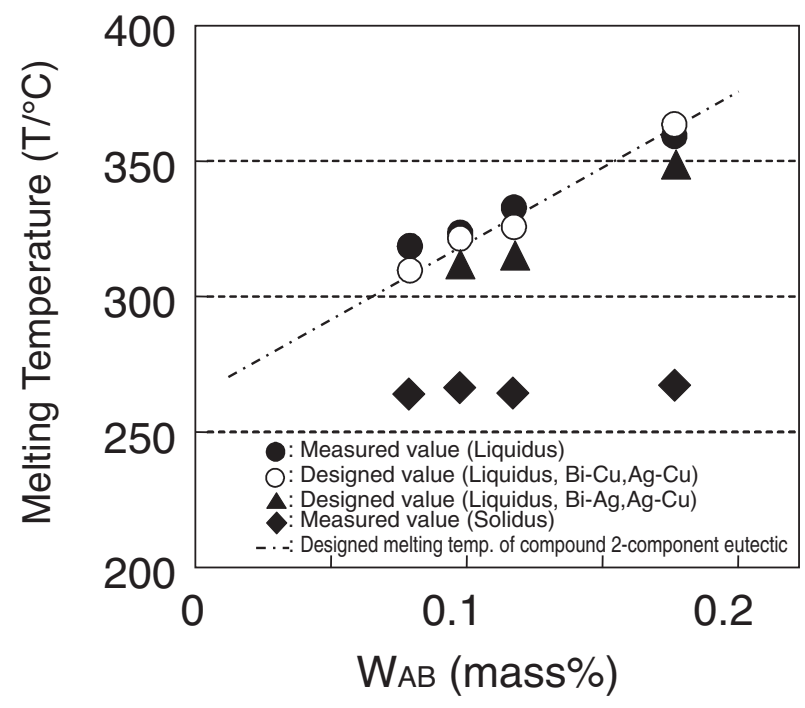

Fig. 3 High temperature solders and melting temperatures. 


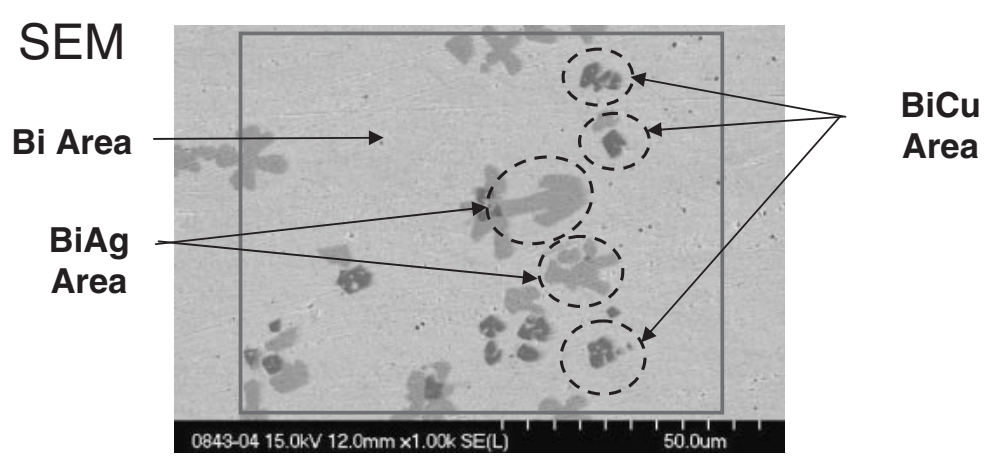

Mapping by EDX (Energy dispersive $\mathrm{X}$-ray analyzer)

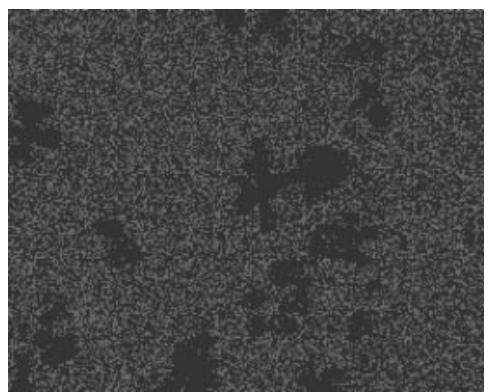

$\mathbf{B i}$

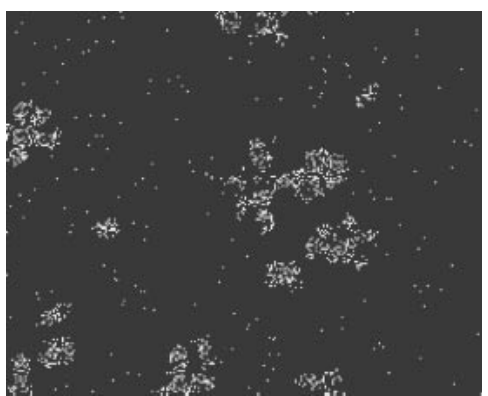

Ag

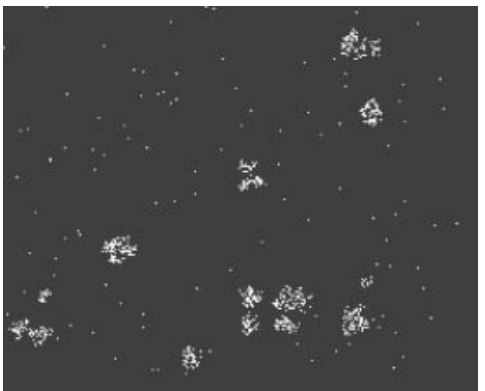

$\mathrm{Cu}$

Fig. 4 Cross-sectional photos of alloys.

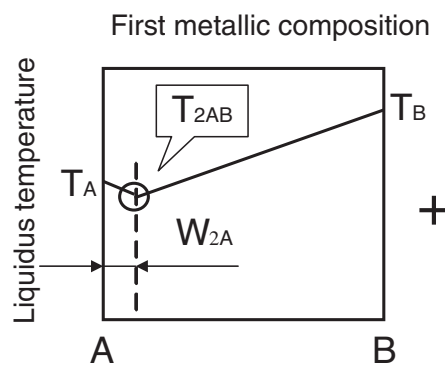

(a)

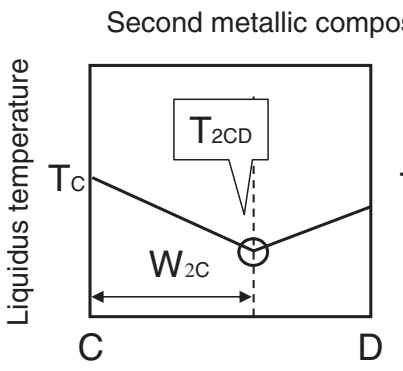

(b)

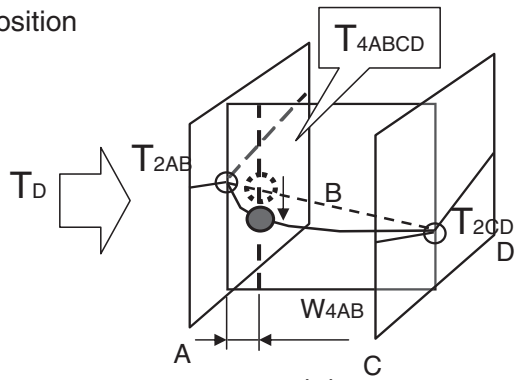

(c)

Fig. 5 Differences between liquidus temperature and designed value.

liquidus temperature of a $\mathrm{Bi}-\mathrm{Ag}-\mathrm{Cu}$ solder was almost the same as the designed melting point temperature of the compounded 2-component eutectic. The reason for the agreement of liquidus and solidus temperatures is believed to be the minimal reaction between the $\mathrm{AB}$ and $\mathrm{CD}$ alloys, as shown in model (B) of Fig. 1.

Examination of the cross-sections of these 4-component fused alloys indicated the $\mathrm{Ag}-\mathrm{Cu}$ and $\mathrm{Bi}-\mathrm{Cu}$ alloys separated and diffused with minimal reaction between them, as shown in Fig. 4. This phenomenon was actually observed in Fig. 4. Though some reaction was seen between $\mathrm{Ag}-\mathrm{Cu}$ and $\mathrm{Bi}-\mathrm{Cu}$, reactions did not occur across the entire zone of these individual 2-component eutectics. Reference in this paper to "minimal reaction" or "mixing difficulty" includes this kind of state.

On the other hand, with the $\mathrm{Bi}-\mathrm{Ag}$ eutectic as the first alloy and $\mathrm{Ag}-\mathrm{Cu}$ as the second, the liquidus temperature was off the design straight line for the compounded 2-component eutectic (Fig. 3), because most likely physical and chemical reactions that led to stress and deformation occurred between the two 2-component eutectics when compounded, as was suggested by model (A) of Fig. 1. In other words, when minimal reaction occurs, the result could be close to a straight line as in model (C) of Fig. 2, but if physical and chemical reactions that lead to stress and deformation occur, a straight line will not be obtained, as in the case of model (C) of Fig. 5. This tells us that the melting temperature of the 4-component solder made by compounding two 2-component eutectics is not linear with respect to the weight percentage of two metallic alloys, hence the difference between the measured and designed liquidus temperatures shown in Fig. 5(C).

The reason why the solidus temperature deviates from the designed melting straight line of Fig. 3 is believed to be the difference in melting point of the various component alloys as they each start melting from the solid state at different times. This allows thermal reactions to occur in-between the solid and liquid phases, hence causing the measured temperature to deviate from the design straight line of the 2- 

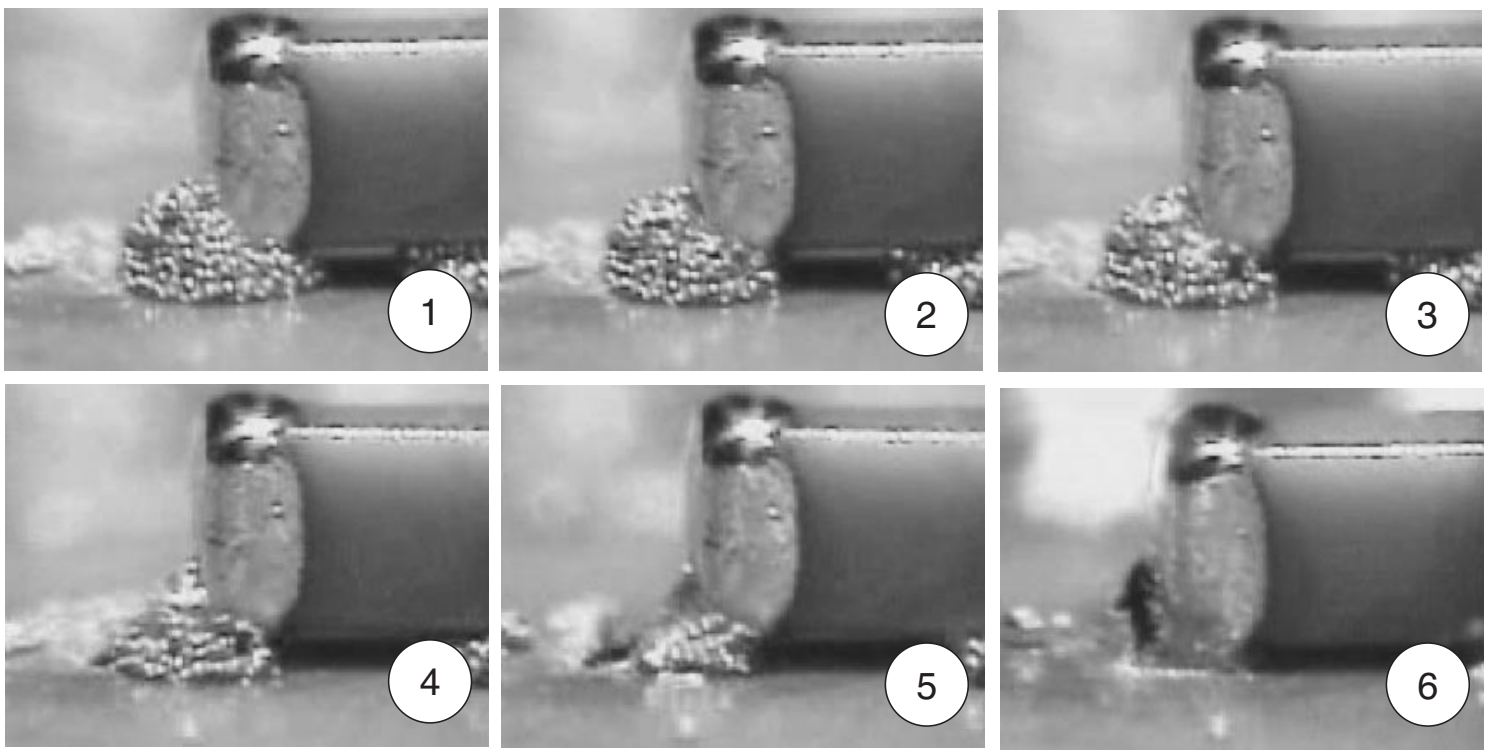

Fig. 6 Solder melting process

component eutectic. To confirm this, $\mathrm{Bi}-\mathrm{Ag}$ eutectic powder and $\mathrm{Ag}-\mathrm{Cu}$ eutectic powder were mixed and melted to a solder state by hot air blow. The mixing process of the two types of 2-component eutectic solders was captured by timeelapsed recording using a high speed video camera, which is shown in the photographs of Fig. 6. There, it can be seen how the solder particles gradually melt and change. More specifically, melted and unmelted alloys mix whereby destabilizing the thermal equilibrium, which causes the solidus temperature to deviate from the design temperature.

\subsection{Melting points of solder components and melting temperature design straight line of compounded 2- components eutectics}

Section 5.1 described high temperature materials of a $\mathrm{Bi}-$ $\mathrm{Ag}-\mathrm{Cu}$ system, but similarly, studies were made into the relationship of measured melting temperatures and melting temperature design straight lines of compounded 2-component eutectics of low and medium melting point materials.

Since the liquidus temperature of conventional solder was already known, it was set as the target temperature. A design melting point was then calculated and the correspondence to this straight line was investigated.

The first solder was the $\mathrm{Sn}-57 \mathrm{Bi}-1 \mathrm{Ag}$ eutectic that is currently used as a low temperature lead-free solder. The target melting point was set at $138^{\circ} \mathrm{C}$. As shown in Fig. 1(B), this solder consists of 2-component eutectics in $\mathrm{Sn}-\mathrm{Bi}$ and $\mathrm{Bi}-\mathrm{Ag}$. Interactivity between these two alloys is believed non-existent. When plugged into the five formulas of Section 3 and computed, the $\mathrm{Sn}-\mathrm{Bi}$ eutectic results $99.0 \%$ and the $\mathrm{Bi}-$ $\mathrm{Ag}$ eutectic $1.0 \%$, and, since the composition is $\mathrm{Sn}-57.5 \mathrm{Bi}-$ $1.0 \mathrm{Ag}$, the designed melting point temperature came out to $139.2^{\circ} \mathrm{C}$.

The second solder was $\mathrm{Sn}-3 \mathrm{Ag}-0.5 \mathrm{Cu}$ for which the target melting point was set at $220^{\circ} \mathrm{C}$. It consisted of 2-component eutectic alloys in $\mathrm{Sn}-\mathrm{Ag}$ and $\mathrm{Sn}-\mathrm{Cu}$. When plugged into the formulas and computed, the $\mathrm{Sn}-\mathrm{Ag}$ eutectic's weight was $55.2 \%$ and the $\mathrm{Sn}-\mathrm{Cu}$ eutectic's was $44.8 \%$, and, with a composition of $\mathrm{Sn}-2.8 \mathrm{Ag}-0.5 \mathrm{Cu}$, the designed melting point temperature resulted $223.7^{\circ} \mathrm{C}$.

The third solder was an $\mathrm{Sn}-3 \mathrm{Ag}-2.5 \mathrm{Bi}-2.5 \mathrm{In}$ solder with a target melting point of $213^{\circ} \mathrm{C}$. It consisted of 2-component eutectics in $\mathrm{Sn}-\mathrm{Ag}$ and $\mathrm{Bi}-\mathrm{In}$. When plugged into the formulas and computed, the weight of the $\mathrm{Sn}-\mathrm{Ag}$ eutectic resulted $94.5 \%$, whereas that of the $\mathrm{Bi}-\mathrm{In}$ eutectic resulted $5.5 \%$. It was made with a composition of $\mathrm{Sn}-4.7 \mathrm{Ag}-1.9 \mathrm{Bi}-$ 3.6In, so the designed melting point temperature was $212.8^{\circ} \mathrm{C}$.

The fourth solder was a $\mathrm{Sn}-8 \mathrm{Zn}-3 \mathrm{Bi}$ eutectic of a targeted $197^{\circ} \mathrm{C}$ melting point. It was composed of 2-component eutectics in $\mathrm{Sn}-\mathrm{Zn}$ and $\mathrm{Sn}-\mathrm{Bi}$. When plugged into the formulas and computed, the weight of the $\mathrm{Sn}-\mathrm{Zn}$ eutectic resulted $94.8 \%$, whereas that of the $\mathrm{Sn}-\mathrm{Bi}$ eutectic resulted $5.2 \%$. It was made with a composition of $\mathrm{Sn}-8.5 \mathrm{Zn}-3 \mathrm{Bi}$, so the designed melting point temperature was $194.9^{\circ} \mathrm{C}$.

The designed and measured values as well as the melting point temperatures are summarized in Table 1. When plotted on a graph, these values look as shown in Fig. 7. Here, it can be seen that all of the tested solders, from low to medium temperature, fall on the melting temperature design straight line of the compounded 2-component eutectics.

From these results, it was verified that the difference between the designed melting temperature and the measured melting temperature was within $1.65 \%$. Furthermore, these results show that the aforementioned design method can be used to calculate the weight of alloys $\mathrm{AB}$ and $\mathrm{CD}$ at a target temperature $\mathrm{T}$, thereby obtaining the weight of each component. It is thus believed possible to design many materials including low temperature lead-free solders, such as those shown as in Fig. 7, and high temperature solders.

Incidentally, separately from the solidus temperature studied for the high temperature solders of Section 5.1, we also investigated solidus temperatures for medium temperature solders that contained In. The solidus temperature of $\mathrm{Sn}-\mathrm{Bi}-\mathrm{In}$ deviated from the design straight line for the 2component eutectic in some cases. This is believed due to the 
Table 1 Error between Designed and Measured Melting Temperatures.

Low temperature solder

\begin{tabular}{|c|c|c|c|c|}
\hline \multicolumn{2}{|l|}{ Designed value } & \multicolumn{2}{|c|}{ Measured value } & \multirow[b]{2}{*}{ Error $(\%)$} \\
\hline Alloy composition & $\begin{array}{l}\text { Melting point } \\
\qquad\left({ }^{\circ} \mathrm{C}\right)\end{array}$ & Alloy composition & $\begin{array}{l}\text { Melting point } \\
\quad\left({ }^{\circ} \mathrm{C}\right)\end{array}$ & \\
\hline Sn-57.5Bi-1.0Ag: [0.99(Sn-Bi), $0.01(\mathrm{Bi}-\mathrm{Ag})]$ & 139.2 & $\mathrm{Sn}-57 \mathrm{Bi}-1 \mathrm{Ag}$ & 138 & -1.22 \\
\hline \multicolumn{5}{|l|}{ Medium temperature solder } \\
\hline \multicolumn{2}{|l|}{ Designed value } & \multicolumn{2}{|c|}{ Measured value } & \multirow[b]{2}{*}{ Error $(\%)$} \\
\hline Alloy composition & $\begin{array}{l}\text { Melting point } \\
\left({ }^{\circ} \mathrm{C}\right)\end{array}$ & Alloy composition & $\begin{array}{l}\text { Melting point } \\
\quad\left({ }^{\circ} \mathrm{C}\right)\end{array}$ & \\
\hline $\mathrm{Sn}-2.8 \mathrm{Ag}-0.5 \mathrm{Cu}:[0.552(\mathrm{Sn}-\mathrm{Ag}), 0.448(\mathrm{Sn}-\mathrm{Cu})]$ & 223.7 & $\mathrm{Sn}-3 \mathrm{Ag}-0.5 \mathrm{Cu}$ & 220 & -1.65 \\
\hline Sn-4.7Ag-1.9Bi-3.6In: [0.945(Sn-Ag), 0.055(Bi-In)] & 212.8 & $\mathrm{Sn}-3 \mathrm{Ag}-2.5 \mathrm{Bi}-2.5 \mathrm{In}$ & 213 & 0.09 \\
\hline $\mathrm{Sn}-8.5 \mathrm{Zn}-\mathrm{Bi}:[0.948(\mathrm{Sn}-\mathrm{Zn}), 0.052(\mathrm{Sn}-\mathrm{Bi})]$ & 195 & $\mathrm{Sn}-8 \mathrm{Zn}-3 \mathrm{Bi}$ & 197 & 1.03 \\
\hline
\end{tabular}

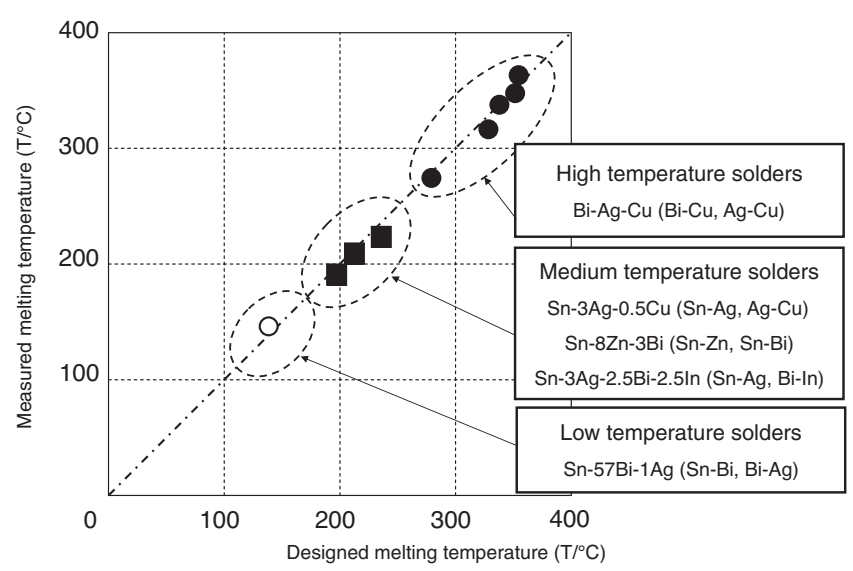

Fig. 7 Designed and measured melting temperatures.

same reasons seen with the high temperature solders studied in Section 5.1.

\subsection{Expansion to multiple component lead-free solder alloys}

In this paper, it is possible for the apparent liquidus temperatures of the departure materials (two 2-component eutectic alloys) to agree with hypothetic values even if they do not readily melt together even when mixed at temperatures at which the components exist in the liquid state, and, from there, surmise the desired liquidus temperature. Given that, the thinking behind the 4-component alloy of Section 2 can be developed for even an 8-component alloy. However, this would present the complicated melting behavior of a multi-component alloy, meaning only an apparent liquidus temperature could be obtained.

As the first alloy, a 4-component material consisting of components $\mathrm{AB}$ and $\mathrm{CD}$ is used. The weight of component $\mathrm{AB}$ in the eutectic state of components $\mathrm{AB}$ and $\mathrm{CD}$ is $W_{4 \mathrm{AB}}$. The eutectic temperature in this case is $T_{4 \mathrm{ABCD}}$.

As the second alloy, a 4-component material consisting of components $\mathrm{EF}$ and $\mathrm{GH}$ is used. The weight of component $\mathrm{EF}$ in the eutectic state of components EF and GH is $W_{4 \mathrm{EF}}$. The eutectic temperature in this case is $T_{4 \mathrm{EFGH}}$. The graph that connects the eutectic temperatures of the first and second alloys is shown in Fig. 8(C). With $T$ as the target temperature and $W_{8 \mathrm{ABCD}}$ as the weight of first alloy eutectic components $\mathrm{AB}$ and $\mathrm{CD}$ against the whole of the 8-component system, the formula is obtained as follows.

$$
W_{8 \mathrm{ABCD}}=\left(T_{4 \mathrm{EFGH}}-T_{8 \mathrm{~A}-\mathrm{H}}\right) /\left(T_{4 \mathrm{EFGH}}-T_{4 \mathrm{ABCD}}\right)
$$

Moreover, the weight of component $\mathrm{AB}$ in the 8-component system, $W_{4 \mathrm{AB}}$, is obtained using $W_{8 \mathrm{ABCD}}$ in the following formula.

$$
W_{4 \mathrm{AB}}=W_{8 \mathrm{ABCD}} \times W_{8 \mathrm{~A}-\mathrm{H}} .
$$

Furthermore, the weight of component $\mathrm{A}$ in the 4-component system, $M_{4 \mathrm{~A}}$, is obtained with formula (2).

Using this same train of thought, the target temperature can be estimated and the weight of solder components can be determined even for an 8-component system. And, it can be applied not only to an 8-component system but materials that combine many more components.

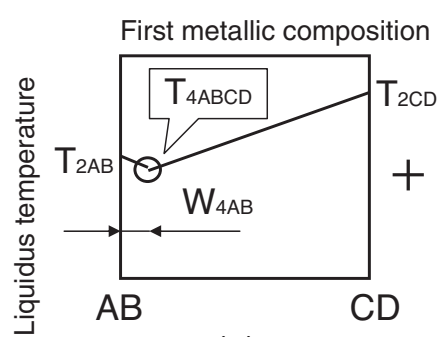

(a)

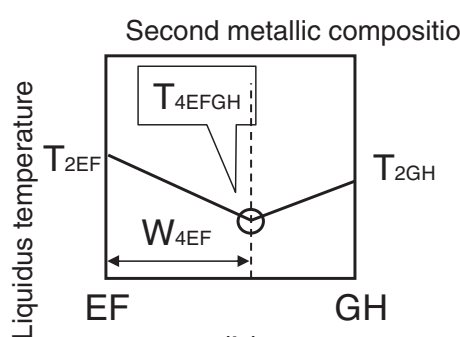

(b)

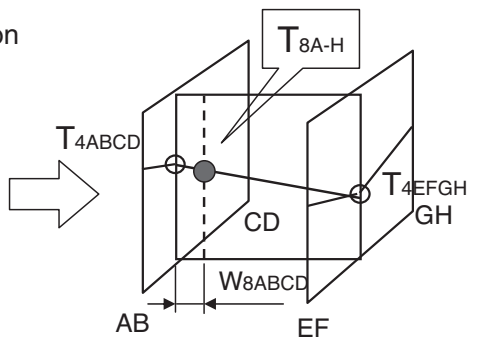

(c)

Fig. 8 Designing 8-component solder alloys. 


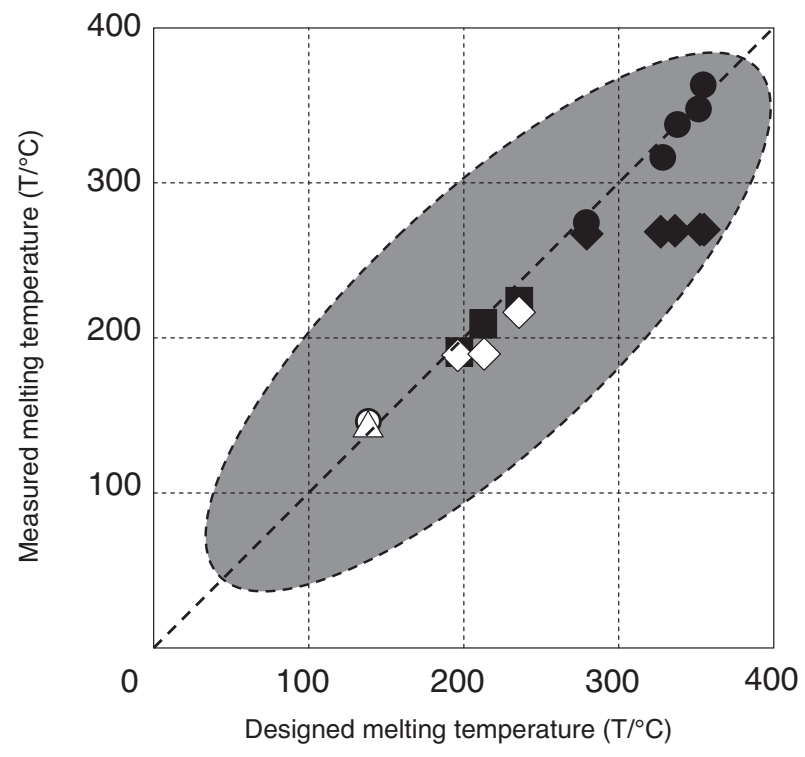

Fig. 9 Possibility map of new lead-free solders.

\subsection{Diversification of lead-free solder materials and development of scientific searches}

Using an ideal straight line for compounded 2-component eutectics, it should be possible to convert conventional point searches to linear searches. Moreover, it should be possible to obtain lead-free solder materials in the domain of the diagonal line shown in Fig. 9. The materials on this diagonal line should be possible new lead-free solders.

These materials are typical lead-free solder alloys such as $\mathrm{Sn}-\mathrm{Bi}-\mathrm{Ag}, \mathrm{Sn}-\mathrm{Ag}-\mathrm{Bi}-\mathrm{In}, \mathrm{Sn}-\mathrm{Zn}-\mathrm{Bi}, \mathrm{Sn}-\mathrm{Ag}-\mathrm{Cu}$ and $\mathrm{Bi}-$ $\mathrm{Ag}-\mathrm{Cu}$ alloys. This opens up the possibility of developing lead-free solder for the internal bonds of high frequency modules of cellular phones and other high temperature, high reliability fields such as PDP and automotive, which are looked at currently as development targets. In relation to this, the demand is growing for high temperature solders and high reliability solders such as those explored in this paper. To meet this demand as quickly as possible, theoretical analyses using thermodynamics are absolutely necessary. However, the solder materials mentioned in this paper take a long time to react together and, because their apparent diffusion is slow, are dealt with in a state of non-equilibrium. They are not practical because their free energy is not in thermodynamic equilibrium. For this reason, the thermodynamic approach cannot be applied at present to materials that do not readily react. Therefore, we are examining the possibility of developing a 4-component system that is not completely blended as an approach to this state of non-equilibrium; that is to say, the starting point is a 4-component system in which mixing entropy has not occurred. In the thermodynamic formula of this 4-component system, the mixed energy $G_{A B}$ of a 2-component system consisting of materials $\mathrm{A}$ and $\mathrm{B}$ would be the sum of the initial mixed energy $G_{0}$ and RT $\left(\mathrm{X}_{\mathrm{A}} \ln \mathrm{X}_{\mathrm{A}}+\mathrm{X}_{\mathrm{B}} \ln \mathrm{X}_{\mathrm{B}}\right)$. For the other two components $\mathrm{C}$ and $\mathrm{D}$, $\mathrm{G}_{\mathrm{CD}}$ would be the sum of the initial mixed energy $\mathrm{G}_{0}$ and $\mathrm{RT}$ $\left(\mathrm{X}_{\mathrm{C}} \ln \mathrm{X}_{\mathrm{C}}+\mathrm{X}_{\mathrm{D}} \ln \mathrm{X}_{\mathrm{D}}\right)$. The mixed energy of this 4-component system $G_{A B C D}$ would seemingly be the sum of the product of $\mathrm{W}_{4 \mathrm{AB}}$ and $\mathrm{G}_{\mathrm{AB}}$, and the product of $\left(1-W_{4 \mathrm{AB}}\right)$ and $\mathrm{G}_{\mathrm{CD}}$ (see Fig. 10.). In describing the thermodynamic formula of the non-equilibrium state that is the starting point of the aforementioned train of thought, due consideration must be given to the correlation between theoretical equations and test values. At present, studies are being directed into nonequilibrium thermodynamic formulas that can be used in the development of high temperature solder.

\section{Conclusions}

It was found that, with two types of 2-component eutectic alloys that do not readily melt together, the apparent liquidus temperature agreed with values calculated using the weight ratios of the respective eutectic alloys, making it possible to estimate a desired liquidus temperature. Regarding this liquidus temperature curve for lead-free solder materials, it was found uniformly possible to predict the liquidus temperature of solders from low temperature systems to high temperature systems by using this approximation theory for compounded 2-component eutectics. Moreover, it is thinkable that the melting design curve for compounded 2component eutectics could be applied to the 4-component eutectic considered in this paper, as well as to multipleelement eutectics such as 8-component systems.

Though more scientific corroboration and observation lies ahead, this design method for predicting liquidus temperature will hopefully mark the beginning of a material design method for developing various types of high temperature lead-free solders such as that for semiconductor die bonds and high reliability solders for automotive products.

To control the melting point of these lead-free solders, analyses from a thermodynamic approach are absolutely essential. In fact, the thermodynamic approach raised in this paper, which describes a material system in a state of non-

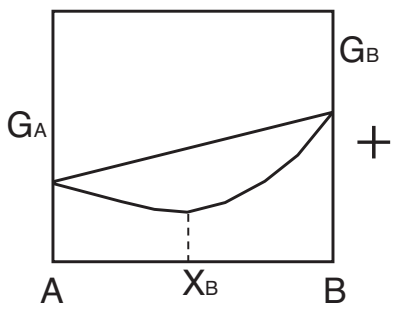

(a)

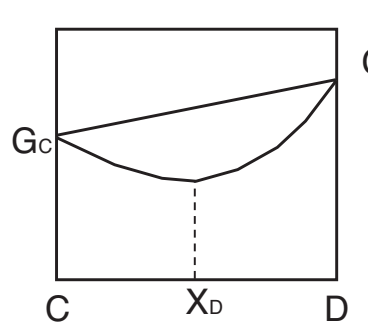

(b)

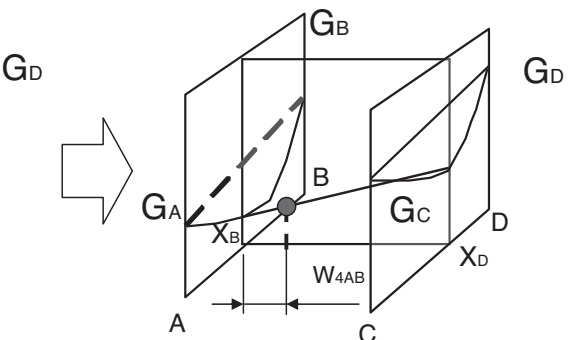

(c)

Fig. 10 Free energy model of 4-component systems. 
equilibrium that requires a long time to melt together and is apparently slow in diffusing, had not been obtained before. Amidst future studies into various material systems, we believe it is an urgent issue to build a thermodynamic theory that can explain this state of non-equilibrium as quickly as possible.

\section{REFERENCES}

1) K. Suetsugu: Development and Practical Application of Lead-Free Solder Bonding Technology (Materia Japan) 38 (1999) 964-967.
2) A. Furusawa, K. Suetsugu and H. Yokoyama: Progress in Lead-Free Solder Technology and Applications (Matsushita Technical Journal) 49 (2003) 85-90.

3) Y. Ikegami, M. Iwazumi and S. Tero: Physical Chemistry IIThermodynamic Theory of Speed (Maruzen Publishing) (1996) pp. 7881.

4) G. Tammam: Z. Anorg. Allg. Chem. 107 (1919).

5) E. C. Ban: Chem. Met. Eng. 28 (1923) 65.

6) C. H. Johansson and J. O. Linde: Ann Phys. K 78 (1925) 439

7) W. L. Bragg and E. J. Williamsi: Proc. R. Soc. A 145 (1934) 699.

8) W. L. Bragg and E. J. Williamsi: Proc. R. Soc. A 145 (1935) 540. 